\title{
Negotiated environmental and occupational health and safety agreements in the United States: lessons for policy
}

\author{
Nicholas A. Ashford *, Charles C. Caldart \\ Massachusetts Institute of Technology, Room E40-23, Cambridge, MA 02139, USA
}

Accepted 14 July 2000

\begin{abstract}
The interest in so-called voluntary approaches to supplement or replace formal environmental, or occupational health and safety regulation has taken on new importance in both Europe and the United States. These approaches fall into two sharp divisions: (1) industry-initiated codes of good practice focusing on environmental management systems or performance goals, and (2) negotiated agreements between government and individual firms or industry sector trade associations focusing on regulation or compliance. This paper addresses the latter.

In the United States, the motivations behind negotiated agreements are manifold and sometimes contradictory including desires (1) to facilitate the achievement of legislated or mandatory environmental goals by introducing flexibility and cost-effective compliance measures, (2) to negotiate levels of compliance (standards) fulfilling legislative mandates, (3) to negotiate legal definitions of Best Available Technology and other technology-based requirements, and (4) to weaken environmental initiatives. Efforts in furtherance of negotiated agreements have thus been greeted with mixed results by the various stakeholders. In the context of an anti-regulatory climate in the United States, the Administrative Procedures Act has been amended to allow "negotiated rulemaking" in achieving regulatory agency mandates. However, even before this legal innovation, regulatory agencies have been negotiating regulations. Independent of this legal avenue, negotiated compliance with industry associations is being fostered through the Environmental Protection Agency's (EPA's) "Commonsense Initiative" and with individual firms through "EPA's Project XL", again with mixed reception.

The proposed paper describes and analyses negotiated agreements in the United States in the context of (1) EPA efforts to ensure environmental protection and (2) the Occupational Safety and Health Administration efforts to ensure worker health and safety. These agreements can be described according to the following taxonomy: (a) Negotiated regulation (either preceding formal regulation or as a substitute for formal regulation); (b) Negotiated compliance (implementing regulation or informal agreements) (i) the means and timetable for coming into compliance with emission, effluent, or concentration requirements (ii) negotiation in the context of an enforcement action in which the firm is out of legal compliance (for example, encouraging cleaner production through the leveraging of penalty reductions).

The criteria for evaluation include: environmental or health and safety outcomes, effects on stimulating technological change, time for development (time to completion)/implementation (likelihood of court challenge), stakeholder influence (ability of large firms to dominate outcome, environmentalists-industry, or labour-management balance of power),and administrative features. () 2001 Elsevier Science Ltd. All rights reserved.
\end{abstract}

Keywords: Environmental negotiation; Occupational health and safety; Negotiated rule making; Negotiation; Voluntary agreements

\section{Introduction}

Negotiation - as an alternative or an adjunct to the adversarial process - is increasingly touted as the wave

\footnotetext{
* Corresponding author. Tel.: +1-617-253-1664; fax: +1-617-2531654.

E-mail address: nashford@mit.edu (N.A. Ashford).
}

of the future. Negotiation, it is argued, is a more efficient use of societal resources, because it is more likely to produce a result which all sides can accept. Moreover, negotiation is said to be more likely to produce creative solutions, because it forces the parties to focus on cooperation rather than confrontation. This article surveys the use of negotiation in formulating and implementing environmental and occupational health and safety policy in the United States, and attempts to assess the potential 
of negotiation to (a) foster improved environmental and health and safety outcomes and (b) stimulate technological change.

\section{Modes of negotiation}

In a broad sense, there are three major instances in which negotiation is used to make or effectuate policy within the federal administrative system of the United States. First, there is negotiated rulemaking, wherein negotiation is used to help set regulatory standards. Second, there is what we call negotiated implementation, where negotiation is used to determine how a regulatory standard, once set, is to be applied to a particular firm (or other member of the regulated community). Under United States environmental statutes, negotiated implementation often occurs when a permit is being issued or revised, as is the case with EPA's recent Project $X L$ initiative. Such negotiation also occurs when the regulated firm seeks a waiver or variance from the regulatory standard at issue. Of particular interest here are the innovation waivers that have been made available by Congress in certain environmental statutes. When such a waiver is granted by EPA, the firm is given additional time to comply with the standard so that it may perfect a promising innovative compliance technology. Similarly, the Occupational Safety and Health Act (OSHAct) authorises OSHA to grant waivers to selected firms who need additional time to perfect new and improved technologies to protect worker health or safety.

Third, there is negotiated compliance, where negotiation is used to determine the terms by which regulatory standards will be enforced against a particular firm (or other regulated entity) that is out of compliance with a particular regulatory standard. By its nature, of course, almost all enforcement involves some amount of negotiation between the enforcing agency (or, in the case of citizen enforcement suits, the enforcing citizen) and the alleged violator. Of interest here are those compliance negotiations that result in (a) compliance through the use of innovative technology, and/or (b) environmental or public health or safety gains beyond compliance. Within the past decade, EPA has pioneered the use of what it terms "Supplemental Environmental Projects" in an attempt to meet these goals within the compliance context.

In the environmental arena, there is also what might be classified as a fourth type of policy-relevant negotiation. Within the current EPA administration, this is what is known as regulatory reinvention. The most prominent example of this is what is known as EPA's Common Sense Initiative, wherein the agency has assembled groups of interested parties to focus on regulatory issues concerning a particular industry sector (e.g., automobile manufacturing), with an eye toward developing "cleaner, cheaper, smarter" ways of reducing or preventing pollution.

\section{Negotiated rulemaking}

Since the mid-1970s, many commentators in the United States have advocated the use of negotiated rulemaking as a more efficient, sensible alternative to the traditional "notice and comment" procedure typically followed by federal agencies in the development of regulations. Occasionally in the 1970s, and more often in the 1980s, EPA, OSHA, and other federal agencies used the negotiation process as an aid to the development of certain regulations. In 1990, Congress formally endorsed negotiated rulemaking with the passage of the federal Negotiated Rulemaking Act, and the Clinton Administration has been a strong supporter of its use.

\subsection{The performance of negotiated rulemaking as a means of saving time and limiting judicial challenge}

Those who advocate negotiated rulemaking - including Congress - tend to identify two primary benefits that are expected to flow from its use: reduced rulemaking time, and decreased litigation over the final rule. Presumably, face-to-face meetings among the interested parties will be able to avoid the various bureaucratic quagmires that can delay the drafting of a rule within an agency, and will, on average, produce a proposed rule more quickly. Further, since the interested parties have agreed on the wording of the proposed rule in advance, the notice and comment procedure presumably will be less contentious and time-consuming, and the incentive for anyone to file a judicial challenge to the final rule presumably will be slight.

In practice, however, it is not at all clear that negotiated rulemaking delivers on either of these promises. Of all the federal agencies in the United States, EPA has used negotiated rulemaking the most often. A recent study [1] of EPA negotiated rulemakings has concluded that: (a) on average, the promulgation of EPA rules through negotiated rulemaking took no less time than did the promulgation of a "control" group of similar EPA rules through traditional notice and comment rulemaking; and (b) $50 \%$ of EPA's twelve finalised negotiated rulemakings were the subject of legal challenge, compared with a litigation rate of $26 \%$ for all EPA rules issued during the period from 1987 through 1991. To date, then, it has not been established that negotiated rulemaking actually returns the primary benefits touted by its proponents.

\subsection{The performance of negotiated rulemaking as a means of securing a "better" rule}

Nonetheless, there may be other advantages of using negotiated rulemaking, at least in certain circumstances, 
depending on the goals one wishes to achieve. Significantly, because it facilitates face-to-face discussions among rulemaking "adversaries" that might not otherwise occur, negotiated rulemaking holds out the potential that, as differences are understood and addressed, creative solutions may be found to difficult issues in such a way that a substantively better rule emerges. Such a result might come, for example, through the identification of opportunities for innovative technological responses within the regulated community.

As an initial attempt at determining whether this potential is being realised, this article examines three negotiated rulemakings used by EPA to set air emission standards under the federal Clean' Air Act, and four instances in which negotiation was used in an attempt to develop a standard under the Occupational Safety and Health Act (OSHAct) governing occupational exposure to toxic chemicals.

In addition to the limitations imposed by the small number of examples examined, the problem with an analysis of this nature is that any attempt to identify a "better" result is a qualitative exercise: depending on the context, it can mean quite different things to different people. For the purposes of this article, we have sought to evaluate the quality of the final rule produced by negotiated rulemaking according to whether it produced a rule that was more - or less - protective of environmental or occupational health than might have been expected had negotiated rulemaking not been used. Further, we have given particular attention to the extent to which opportunities to promote technological change were - or were not - seized upon by the negotiating committee.

\subsection{Negotiated rulemaking and clean air act emission standards}

Of the twelve negotiated rulemakings completed by EPA through 1996, we have chosen to focus on three that resulted in the promulgation of air emission standards under the Clean Air Act: EPA's woodstoves rule, coke oven emissions rule, and wood furniture coatings rule. We have chosen these three because they share a common set of features: a full committee stayed with the negotiations to the end; the rule negotiated was the rule actually proposed by the agency; and the rule set an air emission standard designed to protect the environment and/or public health.

\subsubsection{The woodstoves rule}

One of EPA's early forays into negotiated rulemaking was the development of a national New Source Performance Standard for "residential wood combustion units" (woodstoves). EPA came to regulate woodstoves as a result of lawsuits brought against the agency by the Natural Resources Defense Council (NRDC) and the
State of New York. That suit sought to force EPA to regulate polycyclic organic matter (POM) as a hazardous air pollutant under Section 112 of the Clean Air Act. As part of its settlement of the POM litigation, EPA agreed to explore the possibility of regulating woodstoves one of the primary contributors of POM - as "stationary sources" of air pollution under Section 111 of the Act. Interestingly, such regulation was desired not only by environmental groups, but also by woodstove manufacturers, who hoped that the promulgation of a national standard by EPA would discourage states from setting their own (likely differing) standards.

Section 111 of the Clean Air Act requires that a New Source Performance Standard (NSPS) reflect the level of emission limitation achievable through the application of the "best system of emission reduction... [that] has been adequately demonstrated." To devise such a national emission standard, EPA convened an advisory committee consisting of representatives from industry, environmentalists, certain states, a consumer group, and the agency itself. Agreement on a single national standard was complicated, however, by the fact that there were two major categories of woodstoves on the market - those that utilised catalytic combusters and those that did not. It was clear that, at least in the short term, the stoves with catalytic combusters were capable of meeting a lower (more protective) emission standard than those without catalytic combusters. Because catalytic combusters require a higher degree of maintenance, however, there was some question as to whether they would continue to deliver this greater level of emission reduction over the long term. Rather than resolve this technical issue, the negotiating committee agreed rather early on to adopt the industry position on the matter, and to propose two standards - one for stoves with catalytic combusters and the other for those without. Thus, the opportunity to diffuse what may well be a superior emission-reduction technology throughout the woodstove industry was lost (as was an opportunity for innovation through the development of new woodstove technology).

This does not necessarily mean, however, that the woodstove rule was a "failure" from an environmental/public health perspective. It is questionable whether Section 111 actually empowers EPA to regulate residential woodstoves as "stationary sources" of air pollution, especially since the rule governs the manufacturers and retailers who sell the stoves rather than the individual homeowners who operate them. Thus, it could be argued that the process of negotiated rulemaking - in which the various players were able to agree on a rule despite itś legal infirmities - resulted in a giant step forward, in that it produced national emission standards which otherwise either might not have been promulgated, or might have been successfully challenged in court.

On the other hand, the Clean Air Act was not the only 
regulatory alternative available to address the woodstove issue. The federal Consumer Products Safety Act (CPSA), which governs the design and sale of products "for use in or around" the home or school, clearly does cover woodstoves sold for residential use, and clearly contemplates regulation of manufacturers and retailers. It is not clear, however, that regulation under the CPSA would necessarily have produced a stricter emission standard for stoves without catalytic combusters. The CPSA requires that the benefits of a consumer products safety standard be justified by its costs, and the members of the non-catalytic industry doubtless would have argued that a stricter standard would have driven them out of the market. Further, unlike EPA, the Consumer Products Safety Commission - a chronically underfunded agency that is often reluctant to take on new issues - had no particular incentive to regulate woodstoves.

\subsubsection{The coke oven emissions rule}

Coke ovens are used to convert coal to coke, which is then used to produce steel. Air emissions from coke ovens come largely from leaking oven doors and lids. In 1992, EPA estimated that some 3.5 million pounds of toxic chemicals, including benzene, phenol, toluene, and polyaromatic hydrocarbons, were emitted to the air annually from coke ovens operating in the US Based on this estimate, EPA put the cancer risk to exposed individuals at 1 in 100 .

Many of the materials emitted by coke ovens are subject to regulation as hazardous air pollutants under Section 112 of the Clean Air Act, and the 1990 amendments to the Act specifically required that Section 112 standards for coke oven emissions be promulgated by December 31, 1992. In early 1992, after meeting with representatives of the steel industry, relevant labour unions, states, and environmental groups "to discuss available data to be used as the basis of [a Section 112 regulation]," EPA convened a negotiated rulemaking committee that drew from all of these constituencies. After several negotiating sessions, the committee agreed on a draft rule that was proposed by the agency in December 1992, and was published as a final rule in October 1993.

In general, Section 112 of the Clean Air Act takes a two-tiered approach to the regulation of hazardous air pollutants. EPA is first to set technology-based emission standards, on an industry-category by industry-category basis. These are commonly known as the "MACT" standards, because they are to be set with reference to the application of the maximum achievable control technology that the industry category can currently achieve. Eight years later, the agency is to set a more stringent, health-based standard if further emission reductions are deemed necessary to provide "an ample margin of safety to protect public health." A health-based standard for carcinogens must be set if the technology-based standard fails to "reduce lifetime excess cancer risks to the individual most exposed to [the] emissions...to less than one in one million." For coke oven emissions in particular, however, Section 112 offers an alternative whereby a source may delay compliance with the health-based standard until 2020 if it meets a different, more stringent technology-based standard in the interim. The committee followed this framework in drafting its proposed rule, and steel industry representatives said afterwards that, because they viewed any likely health-based standard as "essentially a shut-down standard," they expected all plants except those that planned to go out of business in the near future to choose this "extended compliance" option.

At the conclusion of the negotiated rulemaking process, participants from environmental groups, labour, industry, and state governments all expressed their satisfaction with the negotiated rule. An EPA representative stated his belief that the negotiated rule would result in more emission reductions than would have been obtained through the conventional rulemaking process, and remarked that the agency had never before "been able to grapple with the economic and technological issues" addressed by the rule. It is probably more accurate to say, however, that this is a rulemaking that was made considerably easier because Congress had taken it upon itself to specify the dates by which - and the minimum amounts by which - the steel industry would be asked to reduce emissions. Indeed, the chief contribution of negotiation to the rulemaking process appears to have been to afford the industry the opportunity to negotiate a standard that actually is less stringent than that which was mandated by Congress.

For coke oven facilities choosing the "extended compliance" option, EPA was required to promulgate two sets of technology-based emission limits by December 31, 1992, to become effective in November 1993 and January 1998, respectively. Emission limits for coke ovens had traditionally been expressed in terms of a maximum permissible percentage of leaking doors, lids, and offtakes, and Congress adopted this approach in Section 112. For the 1993 limits, Congress specified the precise percentages EPA was to require. For the 1998 limits, Congress directed the agency to set percentages "reflecting the lowest achievable emission rate" (colloquially known as "LAER"), and also specified a set of percentages representing the least stringent permissible 1998 standard that EPA could set, and a second set representing a more stringent default 1998 standard that was to take effect if the agency failed to promulgate the 1998 limits by December 31, 1992.

In writing the rule that was promulgated by EPA, the negotiated rulemaking committee began with the 1993 limits specified in the statute, and with the least stringent permissible 1998 limits specified in the statute, but con- 
verted them to "statistically equivalent" limits based on thirty days' average performance. Thus, while the statute specified a maximum percentage that was not to be exceeded, the negotiated rule specifies an average percentage that must be achieved over a thirty-day period. This allows a facility to exceed the percentage specified in the statute for certain periods, so long as it is sufficiently below that percentage for other periods to maintain the required thirty-day average.

This change was made because the steel industry expressed concern that a straightforward application of the standards specified by Congress would necessitate the closure of most of the existing coke oven facilities throughout the country, as they would be unable to meet the specified maximum limits on a continual basis. Union participants in the negotiations, who were interested both in preserving jobs and in reducing workplace emissions, apparently helped to persuade the environmental group participants that this concern was a valid one. In addition, the statistical conversion to thirty-day averages allowed EPA and the environmental group representatives to point to regulatory limits expressed as numbers that were actually below the numbers specified by Congress in the statute. For example, the statute requires 8\% leaking doors in the 1993 limits, while the regulation specifies $7 \%$ leaking doors. Even though this difference is simply an artefact of the statistical conversion of the statutory number to a thirty-day average value, the appearance is of a more stringent standard.

From a health perspective, however, the regulation may well be less protective than the numbers specified in the statute. There is evidence that short-term exposure to a certain amount of carcinogenic materials is more harmful than exposure to the same amount of those materials, in smaller daily increments, spread out over a longer term. The increased damage done on the individual days of high exposure levels allowed under the thirty-day average approach, then, may not be offset by the reductions in damage experienced on those days when emissions are below the required average.

Moreover, it appears clear that the negotiated 1998 limits were not set according to the "lowest achievable emission rate" (LAER) as that term is defined in the Clean Air Act. LAER is defined, in relevant part, as "the most stringent emission limitation that is achieved in practice by [the] class or category of source," with no consideration of the cost of meeting that emission limitation. That is, a LAER limit is to be based on the emission levels being attained by the best-performing existing plant within the particular industry class or category. The best-performing coke oven facility in operation in the United States at the time was the Jewell Smokeless plant, in Vansant, Virginia, owned by Sun Coal. This facility employs a nonrecovery coke oven technology, while all of the other coke oven plants in the country employ the older, and dirtier, by-product recovery tech- nology. A nonrecovery plant can achieve an emission limit of $0.0 \%$ leaking doors, lids, and offtakes. Further, nonrecovery plants produce far less wastewater, and far less hazardous waste, than comparable by-product recovery plants, and also generate excess energy that can be utilised elsewhere in the facility. From an environmental perspective, then, the nonrecovery technology is undeniably superior.

Although there was some talk within the negotiated rulemaking committee of basing the LAER limits on the performance of the Jewell Smokeless plant, the committee decided instead to consider the performance of byproduct recovery plants only. The committee apparently focused on the performance of a USX (United States Steel) plant in Clariton, Pennsylvania, which the committee appears to have deemed the best-performing byproduct recovery facility. Yet, as noted, the committee set the 1998 limits simply by specifying percentages that were calculated to be the "statistical equivalent" of the least stringent permissible limits specified in the statute. If the committee took this approach because it believed that this was the best the industry could do, this appears to have been a significant error in assessment.

The negotiated 1998 limits (expressed as thirty-day averages) are $4.3 \%$ leaking doors for tall doors and foundry doors, and 3.8\% leaking doors for all other doors. As LAER limits, these limits were required by statute to be representative of the very best performance within the industry. An EPA survey of by-product recovery plants done six months after these limits were promulgated in 1993, however, found that most plants were easily meeting the 1998 limits, and that some plants were averaging $1 \%$ to $2 \%$ leaking doors. In other words, the best performance in the industry was considerably better than what the 1998 limits allow. Subsequent EPA surveys of the industry revealed that the performance of many of the plants worsened somewhat thereafter, but was still comfortably in compliance with the legallyapplicable 1993 limits. This suggests that the plants may have initially been testing their technology to ensure that they could meet the 1998 limits. In August 1997, with the 1998 limits due to become enforceable within a few months, most of the plants were again meeting the 1998 limits on a continuous basis, and roughly three out of every five of the plants had maximum (as opposed to thirty-day average) values of less than $2 \%$ leaking doors.

The Clean Air Act also specifies that, by January 2007, EPA is to review the 1998 LAER limits for coke oven facilities, and "revise [them], as necessary...to reflect the lowest achievable emission rate as defined... at the time," with such revised limits to become effective on January 1, 2010. Rather than waiting until later to set the revised LAER standard, so that it could assess technological improvements made in response to the 1993 and 1998 limits, EPA adopted the recommendation of the negotiated rulemaking committee to set the 2010 
standard as part of the 1993 rule. Again based on performance data from the United States Steel plant in Clariton, the limits for 2010 are only slightly more stringent than their 1998 counterpoints, and are considerably less stringent than what the current data indicate the bestperforming by-product recovery plants could meet. The statutory criteria for LAER, then, simply were not met.

EPA was also required to promulgate Section 112 emission limits for new coke oven sources. Once again, the negotiated rule appears to fall short of the statutory mark. The problem is one of scope as well as one of substance. Section 112 defines "new source" as "a stationary source the construction or reconstruction of which is commenced after the [EPA] first proposes regulations under this section establishing an emission standard applicable to such source." By the terms of the statute, then, a "new" coke oven source includes both the construction of a wholly new coke oven plant and the reconstruction of an existing plant to install a new coke oven battery. Under the terms of the regulation, however, a reconstructed coke oven plant becomes a "new" source only if the new coke oven batteries "increase the design capacity" of the facility. This removes an entire class of reconstructed facility from the ambit of the new source standard, and allows existing plants that do not expand their operations to replace coke oven batteries without making any improvements in technology.

Moreover, new source limits under Section 112 are to be "not less stringent than the emission control that is achieved in practice by the best controlled similar source," without regard to cost. As the Jewell Smokeless nonrecovery plant in Virginia was the best-performing coke oven plant in the United States, one would have expected it to have been the model for EPA's new source standards. Indeed, Congress specified that, in setting new source limits for coke oven facilities, the agency "shall evaluate...the Jewell design Thompson non-recovery coke oven batteries and other non-recovery coke oven technologies." Nonetheless, the negotiated rulemaking committee chose to set two new source standards, one for nonrecovery batteries and one for by-product recovery batteries. New sources choosing nonrecovery technology must meet a limit of $0.0 \%$ leaking doors, lids, and offtakes, while new sources choosing by-product recovery technology need only outperform the $2010 \mathrm{lim}$ its: $4.0 \%$ leaking doors for tall and foundry doors, $3.3 \%$ leaking doors for other doors, $0.4 \%$ leaking lids, and $2.5 \%$ leaking offtakes.

A final noteworthy feature of the negotiated rule is its requirement that compliance monitoring be done on a daily basis, by "certified observers" who are independent of the coke oven facility, but whose funding comes from the industry. Although there have been problems in securing the true "independence" of the observers, there seems to be little question that the rule has enhanced both the frequency and the accuracy of the compliance monitoring. By all accounts, these improvements to the monitoring routine are a direct result of the negotiated rulemaking process.

Overall, however, the rule fashioned by the negotiators was not designed to secure optimal environmental performance from coke oven facilities. The rule provides a framework wherein facilities are assured that, at least until the 2020 statutory target date for health-based limits, emission limits will be attainable through the use of inferior, pre-1993 technology. Indeed, an EPA official noted at the time that companies choosing the "extension track" would be assured that any improvements made to their plants when the rule went into effect in 1993 would be the last they were required to make for almost 30 years. Although this could change if the agency decides to tighten the 2010 limits before the 2007 deadline, the regulation clearly is not designed to encourage diffusion of the cleaner (nonrecovery) technology within the industry, much less to spur any further wholesale improvements in coke oven technology. Further, while EPA touted the negotiated rule as a triumph for "environmental justice" (because coke oven plants tend to be located in heavily-industrialised, lower-income areas), the effect of the negotiated new source standards will be to discourage the use of the cleaner technology in those areas until at least 2020.

This is not to say that the result achieved by the negotiated rulemaking committee may not represent an appropriate balancing of environmental and economic concerns in its approach to a troubled industry. A major stumbling block to tying emission limits to the performance of nonrecovery technology, apparently, was the relatively high capital cost of replacing an existing byproduct recovery battery with a new nonrecovery battery. In addition, there was a concern about jobs. A nonrecovery facility typically employs fewer workers than a by-product recovery facility. Requiring improved performance at existing by-product recovery plants, however, actually created jobs. Negotiated rulemaking appears to have been an ideal vehicle for the discussion of these issues, and for the sharing of information that appears to have been necessary to convince the environmental group representatives to accept the less stringent emission limitations favoured by industry.

However, had the goal instead been to "push" the industry towards markedly better technology, and thus to risk some short-term dislocation within the industry, it is not at all clear that negotiation would have been the best approach. The fact that EPA so grossly underestimated the performance capability of even the existing by-product recovery technology suggests that the agency's limited resources were directed more at ensuring a "successful" negotiation than at ensuring that its technological and economic data base was a reliable one. Reportedly, the negotiated rulemaking process took an immense amount of agency resources. Had EPA instead 
used those resources to take a hard look at what the industry could do, now and in the future, it is likely that the agency could have crafted a rule that met the environmental goals of the Clean Air Act, and that created meaningful incentives for the use of better technology.

\subsubsection{The wood furniture coatings rule}

Another Section 112 regulation that was drafted, in large part, through negotiated rulemaking was the hazardous air pollutant emission standard for the wood furniture industry. After a series of public meetings with representatives from industry, environmental groups, and state government in late 1992 and early 1993, EPA convened a negotiated rulemaking committee to attempt to formulate a rule governing wood furniture (surface coatings) nation-wide. The committee held its first meeting in July 1993, and a proposed rule, largely drafted by the committee, was issued in December 1994. The timing of this promulgation likely was influenced by (if not wholly determined by) the fact that the Sierra Club, a private, non-profit environmental group, had sued EPA in 1993 to compel the issuance of several rules under Section 112, and that a consent decree entered in that case called for the promulgation of this proposed rule by November 21,1994 . The final rule - virtually unchanged from the proposed rule - was promulgated on December 7, 1995, although portions of the rule were challenged in court by the chemical industry.

Based on the committee's work, EPA determined that wood furniture manufacturers performed four basic operations in producing a finished product - finishing, gluing, cleaning and washoff - and the proposed rule contained standards for each. All but the gluing operation standards were drafted by the committee. The standards for the gluing operations were developed "outside of the regulatory negotiation process, because adhesive suppliers were not represented on the Committee." EPA estimated that more than 11,000 facilities were included within the wood furniture industrial source category, and that approximately 750 of these would be considered "major" (as defined by the rule), and thus subject to these regulations under Section 112.

As EPA noted in the preamble to the proposed regulation, "a regulatory negotiation process...often requires concessions from some parties in exchange for concessions from other parties." Considered as a whole, the wood furniture rule might well be viewed as a compromise of the stringency of emission levels in exchange for a clear focus on pollution prevention (as opposed to simply "end-of-pipe" emission control).

For example, Section 112(d) specifies that EPA "may distinguish among classes, types, and sizes of sources within a category or subcategory in establishing [technology-based] standards" for the emission of hazardous air pollutants. Rather than distinguish among the techno- logical and economic capabilities of particular wood furniture industry segments, however, the committee proposed - and EPA accepted - an industry-wide standard. Accordingly, EPA dismissed the suggestion that it require the use of "finishing materials with a very low or zero HAP [hazardous air pollutant] content," on the basis that such materials "have not been demonstrated to be feasible for all industry segments." Had EPA divided the industry into subcategories for regulatory purposes, however, it appears that lower emissions of hazardous air pollutants could have been achieved in certain sectors through the required use of these finishing materials where such use would be feasible.

Further, in the part of the rule dealing with restrictions on certain work practices known to be associated with the release of hazardous air pollutants, the committee specified a list of solvents to be forbidden from use in cleaning or "washoff" activities. Agency technical personnel believed that the committee's list of the chemicals to be so restricted was too narrow and needed to be expanded. Here again, despite these technical concerns, EPA simply accepted the proposed rule as written by the negotiated rulemaking committee.

While the rule drafted by the committee is less stringent than it likely could have been, however, it is designed to encourage pollution prevention, and could ultimately result in changes in technology and practices that reduce emissions below the levels required by the rule. Further, the emphasis on pollution prevention has the advantage of providing protection both to the environment and to workers. Rather than focusing on the use of control technology to reduce emissions, the committee endeavoured to select a format that would "accommodate multiple compliance techniques for the various industry segments. For finishing operations, then, the committee chose to express the required emission limit in terms of $\mathrm{kg}$ (or pounds) of volatile hazardous air pollutants emitted per $\mathrm{kg}$ (or pounds) of solids contained in the finishing materials used. This method of expressing the limit was chosen, noted EPA, because sources are encouraged to reduce the quantity of HAP through reformulation methods."

Significant attention was paid to pollution prevention in the drafting of work practice rules as well. As noted supra, the use of certain solvents is banned in cleaning and washoff operations. In addition, the use of solvents in spray booth cleaning is prohibited except in limited circumstances, and sources are required to maintain a "solvent accounting system" to track the use of solvents in cleaning and washoff. As noted by the agency, "although it cannot be assumed that it will actually result in...reduction, the cleaning and washoff solvent accounting system may prompt facilities to eliminate inefficient uses of solvents."

The fact that this rule included a substantial emphasis on pollution prevention is not surprising. Both the 
decentralised industry profile (with thousands of small shops instead of a few large ones), and the relatively straightforward and uncomplicated opportunities for chemical substitution and use reduction, made this industry an ideal candidate for pollution prevention. Nonetheless, it does appear that the use of negotiated rulemaking facilitated the agency's focus on pollution prevention in the development of the rule. It seems likely that the active participation of industry representatives (who are in the best position to identify productive opportunities for pollution prevention) helped to both deepen and legitimise the committee's efforts to build pollution prevention into the rule.

Moreover, the committee negotiations produced an agreement, outside of the parameters of the rule, under which the industry will prepare a semi-annual "trends report," beginning in 1994, which is to contain "a brief discussion of technologies being used by the industry to reduce emissions, and a discussion of evolving technologies including new finishing materials, adhesives, and improved application equipment." This agreement reflects the belief - apparently shared by many committee members - that "new, lower emitting (both VOC [volatile organic compounds] and HAP) technologies...are...on the threshold of demonstration." In addition, to help determine whether the rule actually results in the targeted reductions in hazardous air pollutant emissions, and to determine whether those emission reductions are being met through the substitution of other hazardous chemicals that are not regulated as hazardous air pollutants, the trends report is to include a chemical use and emission survey from a representative sample of the industry.

\subsubsection{Evaluation}

Table 1 summarises the results of these three negotiated rulemakings in terms of the substantive criteria suggested at the outset: environmental/public health protection and technological change.

The first two columns focus on the particular rulemaking's potential to effect technological change within the regulated industry, where "diffusion" refers to the diffusion of a environmentally-superior existing technology within the industry, and "innovation" refers to the development of a new technology that either produces greater environmental gains than existing technology, or produces equal gains at a lower cost. The second two col- umns refer to the rulemaking's potential to effect improvements in public health or the environment, where "short-term" gains are those that are achieved before new and better technology is developed, and "long-term" gains are those that are achieved when new and better technology is developed and fully implemented.

The woodstoves rulemaking did not seek to push the envelope of woodstove technology, and focused instead on the diffusion of existing control technology. It is assigned a " \pm " rating in the Diffusion column because it set a different emission standard for each of the two types of woodstove technology on the market, rather than seeking to devise a standard that would diffuse the superior technology throughout the industry. This resulted in short-term environmental gain, but did not create a strong, consistent signal designed to encourage the kind of innovation in woodstove technology that might produce greater environmental gain in the longterm.

The profile for the coke oven rule is quite similar. Rather than seeking to diffuse the cleaner existing (nonrecovery) technology, the coke oven rule focused on the use of readily-available control techniques to improve the performance of the dominant existing (byproduct recovery) technology, and has resulted in shortterm environmental gain. Further, by setting a standard for new facilities that is not tied to the performance of the cleaner existing technology, and by setting a 2010 standard for existing facilities that many firms were meeting easily in 1993 , the negotiated rule provides clear incentives for keeping the dirtier technology in operation longer, thus actually reducing long-term environmental gain.

The wood furniture coatings rule, in contrast, has both a focus on pollution prevention - denoted as "+(PP)" and a focus on innovation. It can be expected to diffuse existing pollution prevention technologies and, especially given industry's agreement to prepare the semi-annual trends report, has a real potential to produce innovation (and, concomitantly, to produce long-term environmental gain).

\subsection{Negotiated rulemaking and OSHA toxic substance exposure standards}

Negotiation has also been used as a means of establishing standards for workplace exposure to toxic sub-

Table 1

Technological and environmental impact of three negotiated air emission standards

\begin{tabular}{lllll}
\hline & Diffusion & Innovation & Short-term environment gain & Long-term environment gain \\
\hline Woodstoves & \pm & - & + & - \\
Coke ovens & \pm & - & + & - \\
Wood furniture & $+(\mathrm{PP})$ & $+(\mathrm{PP})$ & + & + \\
\hline
\end{tabular}


stances, and we examine four of those negotiations here. At the outset, it should be noted that not all of the examples chosen represent formal, agency-sponsored negotiation. OSHA has convened a formal "negotiated rulemaking committee" on only four occasions. Two of those dealt with toxic substance exposure standards (for benzene and 4,4'-Methylenedianiline, respectively), and both are presented here. In addition, we have included two instances - involving standards for formaldehyde and butadiene exposures - in which the interested parties negotiated a proposed standard on their own, with no formal encouragement or assistance from OSHA. The four rulemakings are discussed in chronological order.

Before discussing these rulemakings, it is important to note that OSHA also has from time to time used its authority under the OSHAct to establish advisory committees to "assist...in...standard-setting functions" [2]. OSHA does not sit as a member of these committees, and it is not bound by their recommendations. In general, these advisory committees have been true to their name: they have served an advisory function on technical and/or policy issues, but they have not involved an attempt by the committee members to negotiate a proposed rule. The advisory committee established by OSHA to address occupational exposure to coke oven emissions, however, did negotiate a set of agreements that formed the basis for the coke oven emissions standard promulgated by the agency in 1976. Because information on those negotiations is not as well-developed as that which is available regarding the four subsequent negotiations discussed below, we have not included an analysis of the coke oven emissions standard in this Article.

\subsubsection{The benzene standard}

In 1971, as required by the passage of the OSHAct in 1970, OSHA adopted several "national consensus standards" for occupational exposures to hazardous substances. One such standard was a requirement that occupational exposures to benzene not exceed a permissible exposure limit ("PEL") of 10 parts per million ("ppm"), measured as a time-weighted eight-hour average concentration in workplace air. In 1974, however, the National Institute for Occupational Safety and Health (NIOSH) issued a report suggesting that benzene could cause leukaemia. NIOSH issued a revised report in 1976 concluding that no safe level of exposure to benzene could be established, and recommending that the OSHA standard be reduced to $1 \mathrm{ppm}$. Thereafter, after conducting a traditional notice and comment rulemaking, OSHA promulgated a new benzene standard which limited exposures to the recommended $1 \mathrm{ppm}$ level. The new standard was challenged by industry, and was remanded to the agency by the United States Supreme Court in 1980. In a plurality opinion that served as the lead opinion of the Court, four justices concluded that OSHA cannot prom- ulgate a standard limiting exposures to a hazardous substance unless the agency demonstrates that the standard is necessary to reduce a "significant risk of material health impairment," and three justices found that OSHA had failed to bring forth sufficient evidence to demonstrate that benzene exposures below $10 \mathrm{ppm}$ posed a significant risk of harm.

Under pressure from labour unions and public interest groups to push ahead with a revision to the standard, OSHA decided in 1983 to attempt to formulate a new proposed standard through negotiated rulemaking. The benzene rule was thought by OSHA to be a good candidate for negotiated rulemaking, because the parties and the issues had been well-defined over the course of the previous administrative and judicial process. At the same time, however, OSHA also recognised that that same process had tended to polarise and solidify the viewpoints of the opposing parties.

Although the benzene negotiations are given credit for helping to further identify and narrow the issues to be resolved, however, they did not result in a proposed rule. Opinions as to the reason for this "failure" tend to vary. One school of thought holds that the difficulty of the issues, together with the structure of the negotiations, doomed the process to failure. The petroleum industry's fear of tort liability for benzene exposures apparently was a major stumbling block. All of the participants and OSHA - believed that any revised standard would have to meet the "significant risk" test articulated by the Supreme Court's plurality opinion. The petroleum industry was concerned that an official agency declaration that benzene posed a significant risk at a particular exposure level would lead to enhanced tort liability for exposures at or above that level, and industry representatives thus pushed for a proposed rule that tread lightly on the issue of risk. This apparently proved difficult for the negotiators to fit within the OSHAct framework. In the words of commentator Henry Perritt, "[The petroleum industry] hoped to frame a risk finding that would recognise a risk at...10 ppm, but [that] would not say that a risk existed at the new [standard]. The participants, however, were unable to develop language that satisfied both the tort and statutory criteria."1

Substantive problems such as these, it has been argued, were exacerbated by the fact that OSHA itself did not participate in the negotiations. Although OSHA

\footnotetext{
' See Ref. [2] at 1654. Reportedly, there were differences of opinion among the affected industries as to what an appropriate standard would be. The rubber industry had been meeting an exposure level of $1 \mathrm{ppm}$ since the late 1970s. The petroleum and chemical industries believed that they could meet the $1 \mathrm{ppm}$ level only $85 \%$ to $90 \%$ of the time, and thus wanted a $2 \mathrm{ppm}$ standard. The steel industry was having trouble meeting even the existing $10 \mathrm{ppm}$ standard, and opposed any reduction in the standard. [2] at 1651. Labor, on the other hand, did not wish to retreat from the $1 \mathrm{ppm}$ standard originally proposed by OSHA.
} 
organised, and provided part of the financial support for, the negotiations, no OSHA representative was present at the meetings of the negotiating committee. Perritt, for one, believes that OSHA's absence from the negotiations was a major impediment to success: "nonparticipation by...OSHA gave it less of a stake in successful negotiations", and therefore less motivation to use its ultimate power to creative incentives for parties to negotiate meaningfully.

However, later experience with the formaldehyde and butadiene rules - which were negotiated by the interested parties without the participation or the sponsorship of the agency - tends to diminish the suggested significance of OSHA's absence from the process.

Moreover, it appears that another, less subtle, force was at work in helping to scuttle the benzene negotiations. Michael Wright, who participated in the negotiations on behalf of the United Steelworkers of America, reports that, in his opinion, "good progress" was being made on crafting a final standard on which all sides could agree until attorney C. Boyden Gray, on behalf of Vice President George Bush, contacted both labour and industry and assured them that the Administration would not approve any benzene rule with which they were not happy. Industry representatives reportedly took this as an assurance from the Reagan Administration that no benzene rule need be promulgated, and their interest in pushing forward with the negotiations waned accordingly.

After the negotiations stalled, the Steelworkers and others sued OSHA in an attempt to force the promulgation of a revised standard. In response, OSHA submitted a rulemaking schedule to the court in which it committed to promulgating a revised benzene standard according to a specified schedule. OSHA published the final standard in 1987. Significantly, the maximum permissible exposure limit was the same as it had been under the standard that had been invalidated seven years earlier by the Supreme Court: $1 \mathrm{ppm}$. The difference was that OSHA took pains in the administrative record to explain in detail its scientific basis for setting the exposure limit at this level, and to perform a quantitative analysis supporting the agency's conclusion that lowering the benzene standard from $10 \mathrm{ppm}$ to $1 \mathrm{ppm}$ would result in the reduction of a "significant" risk of cancer. In so doing, the agency had the benefit of several additional scientific studies that had been completed since the time of the first benzene rulemaking, including epidemiological studies that strongly suggested that benzene posed a higher cancer risk at $10 \mathrm{ppm}$ than at $1 \mathrm{ppm}$.

Thus, in marked contrast to its first attempt to revise the standard, OSHA constructed a rulemaking record that would be virtually unassailable under any reasoned judicial analysis. This attention to scientific detail in the crafting of the administrative record, together with the filing of the lawsuit that prompted OSHA to engage the rulemaking process in earnest, appear to be the factors most responsible for the ultimate success of the benzene rule.

\subsubsection{The MDA standard}

OSHA's next attempt at negotiated rulemaking dealt with worker exposures to 4,4'-Methylenedianiline ("MDA"), a constituent of paints and other coating materials. In 1983, EPA issued a notice under the Toxic Substances Control Act (TSCA) indicating, on the basis of data from animal bioassays, that MDA may pose a significant risk of cancer to humans. Thereafter, EPA began a formal process to gather additional data on MDA. Two years later, after having determined that MDA posed a likely cancer risk to workers, EPA issued a notice under Section 9 of TSCA inviting OSHA to take regulatory action under the OSHAct, and indicating that EPA would take action under TSCA if OSHA declined. In early 1986 , OSHA responded by issuing a notice indicating that it had determined there was a reasonable basis to conclude that MDA posed a significant risk to the health of exposed workers, and indicating that it would proceed with appropriate regulatory action. Thereafter, OSHA convened a negotiated rulemaking committee. The committee held seven meetings, culminating in the publication in July 1987 of recommendations for a proposed rule limiting occupational exposure to MDA. These recommendations were then incorporated by OSHA into a proposed rule in May 1989, and were promulgated by OSHA as a final rule in August 1992. The standard established an eight-hour average timeweighted PEL for workplace exposure to MDA of 10 $\mathrm{ppb}$; prior to the promulgation of the standard, average workplace exposures to MDA were estimated to be in the $250 \mathrm{ppb}$ range.

There were a number of differences between the MDA negotiations and the benzene negotiations, and many of these may have contributed to the comparative ease with which the MDA rule was negotiated. It may have been important, for example, that the impetus for an MDA regulation came from EPA, and that the participants knew that EPA would issue a regulation if OSHA did not. The negotiators may have preferred to operate within the familiar context of an OSHA regulation, rather than face the more unfamiliar prospect of an EPA regulation under TSCA. What likely was more important, however, were the much more limited number of industries and workers involved, and the relatively modest financial consequences at stake. By OSHA's estimate, only 400 workers were exposed to MDA. Moreover, OSHA estimated that the average cost of complying with the $10 \mathrm{ppb}$ standard would be only $\$ 5450$ per year per employer (for the purchase and maintenance of personal protective equipment). In contrast to the benzene negotiations, then, the perceived costs to industry were inconsequential. 
In its preamble to the final rule, OSHA voiced considerable support for the use of negotiated rulemaking as the means of developing the MDA exposure standard. Further, the preamble expressed the agency's belief that the use of negotiated rulemaking had not involved any sacrifice of principle to expediency. Although noting that "[s]trictly speaking, it appears inappropriate to suggest that human suffering and lives become the trade off items in a mediation attempt," OSHA stressed that negotiated rulemaking "differs from the typical labour-management negotiations[,] where a limited number of issues must be resolved and bargaining or trade-off become the method to form a compromise. The key difference involves the final product expected. On the one hand, a compromise is reached; on the other hand, a consensus is achieved."

In practice, however, this "key difference" between traditional negotiation and negotiated rulemaking appears to have been more conceptual than actual. "Consensus" was defined by the MDA negotiated rulemaking committee as $75 \%$ concurrence of those members of the negotiated rulemaking committee participating in a vote, and OSHA committed itself in the notice of negotiated rulemaking to use the results of the negotiations as the basis for its final rule. Thus, although the committee reportedly voted unanimously on "approximately $90 \%$ of the issues," it does appear that the agency expressed a willingness to accept a "trade off" of worker protection for expediency as the basis for its health standard. Moreover, OSHA demonstrated a willingness to truncate consideration of the relevant health issues in the interest of producing a rule through negotiation. Reportedly, OSHA resisted "active participation by health experts" in the negotiations, because it feared that "committee meetings would turn into a battle of the experts." Although there were persons with toxicological backgrounds on the negotiating committee, some committee members felt that additional access to health professionals especially physicians - would have been helpful.

This is not to say that nothing was gained through the MDA negotiations. The negotiated rule did ultimately result in a substantial decrease in worker exposure to the chemical. Further, even if the negotiations themselves did not focus on specific pollution prevention strategies, the promulgation of the reduced exposure limits tended to create an additional incentive for the manufacture of MDA-free coating materials. Also, committee members reported that the negotiations provided them access to unpublished MDA data in the possession of other committee members, and it is likely that the trust established among committee members during the negotiations was an important factor in these disclosures.

\subsubsection{The formaldehyde standard}

Formaldehyde, one of the most widely used chemicals in modern industry, became a regulatory concern in
1979, when a two-year study conducted by the Chemical Industry Institute of Toxicology concluded that the chemical causes cancer in rats, and concern increased with the development of epidemiological data over the following decade. On December 4, 1987, after traditional notice and comment rulemaking, OSHA issued a formaldehyde standard imposing an eight-hour time-weighted PEL of $1.0 \mathrm{ppm}$. Although OSHA's findings indicated that a PEL of $0.5 \mathrm{ppm}$ would be technologically and economically "feasible" within the meaning of the OSHAct, the agency declined to impose such a limit because it did not believe the attendant risk was "significant". Based on its reading of the Supreme Court's benzene decision - in which a three-justice plurality observed that a risk of death of one in one thousand is one that a reasonable person might well consider significant OSHA had determined that any risk of less than one in one thousand would not be "significant" under the OSHAct. Accordingly, because it had concluded that the risk of cancer posed by formaldehyde exposures of $1.0 \mathrm{ppm}$ or lower would be less than one in one thousand, OSHA determined that any more stringent formaldehyde standard would not be authorised by the OSHAct.

The $1.0 \mathrm{ppm}$ standard was challenged in court by a coalition of labour unions, who sought a standard of 0.5 ppm or below. In 1989 the United States Court of Appeals for the District of Columbia Circuit remanded the standard to OSHA for further consideration. Noting that OSHA's own factual analysis appeared to indicate that the cancer risk at formaldehyde levels below $1 \mathrm{ppm}$ was greater than one in one thousand, the court directed the agency to either set a more stringent limit or explain more fully why it had not done so. Thereafter, the plaintiffs in the litigation met to attempt to negotiate a modified standard, and on June 27, 1990 they presented OSHA with a recommendation calling for a formaldehyde PEL of $0.75 \mathrm{ppm}$. On May 27, 1992, OSHA promulgated a final standard setting the limit at the recommended level.

Given the circumstances, it is not at all surprising that the negotiators were able to agree on a standard more protective than the one that OSHA had proposed. First, of course, the court's invalidation of the original $1.0 \mathrm{ppm}$ standard had sent a strong signal to industry that a more stringent standard likely would be upheld, and the likelihood that OSHA would determine that a $0.5 \mathrm{ppm}$ standard was feasible had created a reasonable presumption that the revised standard would be set at that level. Further, even before OSHA promulgated the $1.0 \mathrm{ppm}$ standard in 1987 , industry concerns over a possible 0.5 ppm standard had prompted the suppliers of formaldehyde-containing resins to develop new resins containing little or no formaldehyde. In part, the development of these new products made it possible for industry to reduce worker formaldehyde exposures at less than half* the pre-promulgation cost estimates. The negotiated 0.75 
ppm standard, then, represented a relatively painless compromise. Indeed, it is fair to say that the very real threat that a more stringent $(0.5 \mathrm{ppm})$ standard would be set by traditional rulemaking made possible the negotiation of a less stringent $(0.75 \mathrm{ppm})$ standard.

\subsubsection{The butadiene standard}

1,3-Butadiene ("butadiene") is used in the production of synthetic rubber, and in the production of a variety of other chemical products and intermediaries. As of 1996, an estimated 9700 US workers at 255 facilities were exposed to this chemical in their workplace. In 1971, OSHA had adopted a "national consensus" PEL for butadiene of $1000 \mathrm{ppm}$ as a time-weighted eight-hour average. In 1983, however, the National Toxicology Program released the results of a study indicating that butadiene causes cancer in rats. Thereafter, OSHA solicited comments and gathered data for a six-year period, culminating in the issuance in 1990 of a proposal to lower the butadiene PEL to $2 \mathrm{ppm}$, with a short-term exposure limit (STEL) of $10 \mathrm{ppm}$ over fifteen minutes. In addition, the proposed standard specified an "action level" of 1.0 $\mathrm{ppm}$, which triggered increased workplace monitoring requirements.

During public hearings on the proposed standard in 1991, labour and industry representatives "began discussions on issues such as the quality and interpretation of scientific data, carcinogenic causality, permissible exposure limits, and economic and technological feasibility." For sometime thereafter, working outside the formal regulatory process, and without the participation of OSHA, the parties attempted to resolve their differences over the proposed standard. Although a number of the companies in the rubber industry reportedly were achieving average butadiene exposure levels of less than 1.0 $\mathrm{ppm}$, industry was seeking a PEL of $4 \mathrm{ppm}$. The union, on the other hand, sought to bring the OSHA standard in line with the performance of these rubber companies, both to reduce exposures in other industries and to put "moral" pressure on the rubber industry to lower exposures world-wide.

The break in the negotiations reportedly occurred in 1995, after the release of an epidemiological study funded by the International Institute of Synthetic Rubber Producers - supporting the conclusion that butadiene exposure was causing cancer among workers at approximately the rate predicted by extrapolations from the animal data. Spurred by this new confirmation of the seriousness of the butadiene risk, labour and industry representatives were able to reach agreement on a set of recommendations, which were presented to OSHA on January 29, 1996. OSHA then reopened its rulemaking process to solicit comments on the recommendations, and the parties to the labour/industry agreement submitted draft regulatory language which translated their regulations into specific requirements. On November 4, 1996,
OSHA issued a final butadiene standard based largely on the language drafted by the labour/industry negotiators.

As recommended by the negotiators, the revised butadiene standard sets an eight-hour PEL of $1 \mathrm{ppm}$, an STEL of $5.0 \mathrm{ppm}$ over 15 minutes, and an "action level" of $0.5 \mathrm{ppm}$. If monitoring reveals that the $0.5 \mathrm{ppm}$ action level is being exceeded, the employer must implement an "exposure goal program" designed to "limit employee exposures to below the action level during normal operations." Such a program is to consist of specified engineering controls, worker training, medical surveillance, and additional monitoring.

OSHA was enthusiastic about the butadiene standard, and about the role played by the negotiations in developing the standard. Without doubt, negotiation facilitated OSHA's adoption of the butadiene standard. It is apparent that the agency deferred both to the tradeoffs and to the timetable of the labour/industry negotiators, and it is not clear what timetable OSHA would have followed in the absence of these negotiations. Certainly, it is conceivable that, absent some other form of outside pressure (such as a union lawsuit seeking to force promulgation), OSHA would not have issued the final standard by 1996 .

It is less clear, however, that the negotiated standard is "more protective" than what OSHA would have produced on its own. After the industry-funded epidemiological study confirmed the carcinogenic risk of butadiene, OSHA was in a strong position to impose a PEL more stringent than the $2.0 \mathrm{ppm}$ standard it had proposed in 1990. The feasibility of a standard below $2.0 \mathrm{ppm}$ was not seriously in doubt, and industry representatives reportedly were concerned that OSHA would set the PEL at $0.5 \mathrm{ppm}$. The negotiated compromise - a PEL of $1.0 \mathrm{ppm}$ and a $0.5 \mathrm{ppm}$ "action level" - thus appeared palatable in comparison. Moreover, in return for their agreement to accept these lower levels, industry representatives were able to secure a compromise on the use of respirators. The 1990 proposed standard had specified - consistent with OSHA policy - that the exposure limits were to be met largely through the use of engineering controls and work practices, and it permitted compliance through the use of personal respirators only for those situations in which the employer could establish that compliance was not otherwise technologically feasible. The negotiated compromise, however, allows compliance through the use of personal respirators during intermittent non-routine peak exposures. In deference to the negotiators, OSHA retained these provisions in the final rule.

Instead of producing a standard that is clearly stronger than the one originally proposed by OSHA, then, the negotiations produced a result that arguably reduces the incentive for meaningful technological change by industry. For, although a $1.0 \mathrm{ppm}$ PEL is more protective than a $2.0 \mathrm{ppm}$ PEL, the workplace technology that is capable 
of meeting $2.0 \mathrm{ppm}$ during routine operation likely will be capable of meeting $1.0 \mathrm{ppm}$ as well. It is achieving these levels during periods of non-routine operation that poses the greater technological challenge. That is why, in the words of the International Institute of Synthetic Rubber Producers (IISRP) in its comments urging OSHA to adopt the compromise language drafted by the negotiators, "industry needed respirator flexibility to accept...lower [exposure limits]." By giving industry the flexibility it wanted on this point, the negotiated standard secured a short-term goal: it hastened the implementation of stricter butadiene exposure limits by assuring that industry would not challenge those limits in court. In the long term, however, the inclusion of such flexibility may also have removed much of the pressure for further technological improvement.

\subsubsection{Evaluation}

There is perhaps no other regulatory agency whose capacity to spur technological change is as well-documented as OSHA's [3] (hereafter the "OTA Report"). Especially in the agency's early years, OSHA's promulgation of toxic substance exposure standards - through the use of traditional rulemaking procedures - has produced technological changes within regulated industries that have markedly improved the health of US workers [3, note 4, 89-95]. The four rulemakings studied here indicate that, measured against the goal of securing a more health-protective standard, negotiated rulemaking has not been an improvement on the traditional rulemaking process. Indeed, negotiated rulemaking appears to have served, at least in part, as a way for OSHA to abdicate its stewardship role under the law.

The formaldehyde and butadiene negotiations, for example, are noteworthy for their lack of involvement by, or direction from, OSHA. In both cases, interested parties began the negotiations on their own volition, sometime after the agency had promulgated a proposed standard. That the parties chose to take these matters into their own hands should not be particularly surprising. In contrast to the environmental arena, the key players in the OSHA negotiated rulemakings - industry and organised labour - have a long history of resolving disputes through negotiation. In a very real sense, negotiation is an important part of their "culture". Moreover, beginning with the installation of an anti-regulatory administration in Washington after the election of President Reagan in 1980, OSHA has generally been less aggressive in promoting the cause of worker health and safety than it was during the first decade of its existence [5]. In the absence of an aggressive regulatory body, the unions have turned both to negotiation and to litigation in an attempt to prod the regulatory process forward.

Although the standards that emerged from the formaldehyde and butadiene negotiations did secure improvements in worker protection, neither case supports the proposition that private negotiations are more likely to protect worker health than is traditional rulemaking. Rather, these negotiations, illustrate that private negotiations can produce results when conditions are right, especially when the regulatory agency fails to seize the opportunities before it. In both cases, a significant event occurring outside the negotiation process - for formaldehyde, the court decision remanding the $1.0 \mathrm{ppm}$ standard, and for butadiene, the industry-funded epidemiological study confirming a meaningful risk of cancer gave the unions a strong bargaining position, and the unions used this to help them achieve consensus on negotiated rules. But these same events had also put OSHA in a strong position to achieve an equally or more protective standard through the traditional rulemaking process. Rather than taking advantage of these opportunities, however, OSHA merely accepted the policy choices made by labour/industry negotiators.

This is nothing new. In 1983, several years before the formaldehyde negotiations, labour and industry representatives met informally to resolve outstanding issues regarding OSHA's cotton dust standard. As with the formaldehyde and butadiene standards, the negotiations began - at the instigation of the parties themselves, and without the involvement of OSHA - after OSHA had issued a proposed standard. Further, as with the formaldehyde standard, the negotiations began after a court ruling on the OSHA standard. The agency's exposure limit for cotton dust had been upheld by the Supreme Court, leaving only certain ancillary issues for resolution. Before it sat down to negotiate with labour, then, the industry knew that a standard incorporating a particular exposure level would be implemented, and it thus was highly motivated to negotiate the process of that implementation. As noted by commentator Henry Perritt, the fact that the parties were able to reach an agreement on these issues that was adopted by the agency "illustrates the possibility of negotiated agreement on controversial rules, without agency participation, when the incentives of the private parties are strong."

As the benzene negotiations suggest, however, meaningful results are much less likely when the incentives are not strong. In contrast to the formaldehyde, butadiene, and cotton dust negotiations, the benzene negotiations came - at the invitation of OSHA - after industry had mounted a successful court challenge to the exposure level originally set by OSHA. The pressure on industry to agree on a protective standard, then, was far from pressing, and negotiations eventually stalled. Indeed, it ultimately took the rigors of the rulemaking process, prompted into action by a union lawsuit, to successfully re-impose the $1.0 \mathrm{ppm}$ standard.

The MDA negotiations, which were initiated by OSHA and which featured OSHA as a key participant, did produce a final rule, even though there was no strong incentive driving the parties to reach agreement. Here, 
however, because relatively few employees were involved, and because the cost of compliance was low, the stakes for industry were not high.

\section{Negotiated implementation}

In contrast to its role when it is enforcing a regulatory standard (discussed in Section 5 below), an agency's role in implementing the standard (that is, when it addresses the question of the timing and the extent of the applicability of the standard to a particular firm) is a circumscribed one. Nonetheless, there are circumstances in which the agency may be able to use negotiation at this stage of the process to encourage innovation and/or incidental environmental or health and safety gains.

\subsection{The environmental protection agency}

Over its history, EPA has made some use of negotiated implementation both within its explicit statutory mandates (with the use of innovation waivers made available under certain environmental statutes) and (with its Project XL program discussed later) outside of them.

\subsubsection{Innovation waivers}

Various United States environmental statutes have had provisions allowing EPA to issue innovation waivers to qualifying firms, thus allowing them additional time to develop innovative approaches to compliance. The Clean Air Act and Clean Water Act both contain provisions authorising EPA to grant innovation waivers in certain circumstances. Under these provisions, EPA is authorised to extend the deadline by which a firm must meet emission or effluent limitations, so long as the agency is persuaded that the firm is actively pursuing an innovative approach to compliance that shows real promise of coming to fruition. Innovation waivers are meant to focus squarely on the innovation of new technology, and are not designed to promote diffusion of an existing technology.

In concept, the innovation waiver makes a great deal of sense. Development of an innovative idea into an operational reality - which often requires several periods of trial and error - can take substantial time, during which a firm might otherwise find itself liable for penalties for violations of emission or effluent standards. The innovation waiver exempts the firm from such penalties during a designated trial period, and offers it the prospect of the cost savings that may be derived from the development of a superior technology. Although it may be unrealistic to expect EPA to use innovation waivers to promote radical process innovation, because of the long time generally' needed to develop the innovation, the agency might well use such waivers to encourage both incremental process innovation and the acceleration of radical innovation already underway.

In practice, however, innovation waivers have been used sparingly by EPA, both because industry has been unsure of their application (and thus has been wary of risking non-compliance), and because the agency has not encouraged their use [6,7]. Success will require EPA to give early, clear, and certain signals to the firm, thus minimising the risk of its technology being found unacceptable. Furthermore, good faith efforts resulting in significant, though not complete, achievement of the pollution reduction goal may need be rewarded by "failsoft" enforcement strategies, such as a reduction of otherwise applicable penalties, if industry is to be persuaded to take a technological and legal risk that the innovation waiver often poses. In this context, one can make a case for "risk sharing" between government and industry in the interest of fostering innovative solutions.

\subsubsection{Extra-statutory efforts: Project XL}

In an effort to add to those opportunities for flexibility that are specifically authorised by statute, such as innovation waivers, EPA sometimes endeavours to incorporate flexibility into its regulatory implementation by agency fiat. A recent example is the Clinton EPA's Excellence in Leadership Project, popularly known as Project XL. The White House announced this program, with considerable fanfare, in a 1995 policy statement, and EPA published a set of guidelines for approving Project XL proposals in 1996.

The basic idea of Project $\mathrm{XL}$ is to allow regulatory flexibility, in return for superior environmental performance, at selected facilities, on a facility-by-facility basis. As conceived, the cornerstone on which Project XL is to rest is negotiation among the regulators, the facility owners, and the affected community, resulting in a Final Project Agreement ("FPA") governing environmental performance at the facility. The underlying rationale for Project XL is the belief that, for appropriately selected (new and existing) facilities, such negotiations can produce a plan for limiting pollutant discharge from the facility that will both cost less, and reduce environmental and public health risks more, than would have been the case under existing regulations. ${ }^{2}$ Although the program is still in its infancy, it is probably fair to say that it has been far from a clear success. Few FPAs have been

\footnotetext{
${ }^{2}$ Negotiation between the agency and the facility owner (sometimes also involving environmental groups and/or local community groups) is commonplace in the permitting process. Project $\mathrm{XL}$ negotiations are different, however, in that they purport to replace current standards with an alternative approach, while traditional permit negotiations generally are over the proper way to apply current standards to the facility in question. Thus, XL purports to be the negotiation of environmental policy, albeit on a facility-by-facility basis.
} 
negotiated, and some of those that have are the subject of considerable debate and opposition.

A fundamental problem with Project XL is that it envisions a kind of regulatory flexibility that has not been authorised by Congress. Because it is not authorised by statute, the regulatory plan set forth in the negotiated FPA does not supersede existing regulations. Thus, to the extent that the regulatory "flexibility" negotiated by the participants involves a failure to comply with certain regulations (even if also involves outperforming certain other regulations), the facility will be operating in violation of the law. And, since relief from existing regulations is precisely what makes this program attractive to the business community, most FPAs can be expected to involve violations of applicable environmental regulations. Indeed, one source reports that a current expression among EPA staff familiar with Project XL is that "if it ain't illegal, it ain't XL." This makes Project $\mathrm{XL}$ an unsafe bet for the participating firm. For, even if EPA and the state give informal assurances that they will not take enforcement action that is inconsistent with the FPA, the agencies cannot guarantee that such enforcement action will not be taken under the "citizen suit" provision of the applicable federal statute.

In theory, the threat of a citizen enforcement suit was to be eradicated (or at least greatly minimised) by the inclusion of the affected community in the negotiation process. Yet this points to a second fundamental problem with XL: the difficulty of defining the relevant "community." Is it limited to those living near the plant, or does it include national and regional environmental groups with an interest in the issue? Does it include labour? Does it include those who speak on behalf of the protection of sensitive populations, or on behalf of disadvantaged neighbourhoods? These are high-stakes issues for two reasons.

First, any interested party who is excluded from the negotiation process is less likely to be satisfied with the result, and thus is more likely to challenge it, through a citizen enforcement suit, a public organising and publicity campaign, or both. Probably the best-known Project XL agreement to date, for example, pertains to Intel Corporation's newest semiconductor production site in Chandler, Arizona. The five-year project agreement, which covers operations at a 720 -acre site, was negotiated among the company, federal and state regulators, and five Chandler residents. Although the participants apparently are satisfied with the FPA negotiated through this process, many non-participants are not. Two vociferous critics have been the Silicon Valley Toxics Coalition, a California-based group that addresses pollution problems in the semiconductor industry, and the Natural Resources Defense Council, a national environmental group. These two groups, who are concerned about the national and industry-wide implications of this agreement as much as, if not more than, its local environmental impacts, have mounted a high-profile campaign against the Intel agreement, and against Project XL itself. This level of opposition clearly indicates that the negotiating committee that devised the regulatory plan for the Intel facility was not representative of the "relevant" community.

Moreover, the composition of the negotiating committee is of obvious substantive importance as well. If important constituencies are left underrepresented, the agreement negotiated is much less likely to be the "right" result. The five community representatives who helped negotiate the Intel agreement were also members of a pre-existing Intel Community Advisory Panel, and were generally representative of a community sentiment that values the important role that Intel has played over the past sixteen years in helping transform Chandler from a small agrarian town into the third fastest-growing city in the United States. While this obviously is a legitimate perspective, it may well not be the one that places environmental and public health protection (much less the health concerns of particularly sensitive populations) at the forefront. Indeed, the tendency of local interests to sacrifice long-term environmental and public health interests in favour of short-term economic gain was one of the factors that drove Congress to begin setting national pollution standards in the 1970s.

One of the beliefs underlying Project XL is that sufficient public involvement and scrutiny at a site can greatly diminish the need for a national regulatory presence. This is unlikely to be the case, however, unless the "public" is broadly and fairly represented, and unless its "involvement" is truly meaningful. At the Intel site, it is not at all clear that the regulatory flexibility negotiated by Intel - such as relaxed permitting requirements for new product lines - is offset by "superior" environmental performance. While EPA concluded that the Intel plant will outperform certain regulatory requirements, there appears to have been no showing that the facility will attain, much less outperform, the current state of art for the semiconductor industry. For example, based on a comparison of projected toxic emissions from the new Intel facility to reported emissions from similarly-sized semiconductor facilities from 1992 through 1994, EPA was able to conclude only that "Intel is well within, if not exceeding, the standard for the industry."

Had groups such as the Silicon Valley Toxics Coalition and the Natural Resources Defense Council been involved as full-fledged negotiating participants at the Intel site, it is likely that any resultant FPA would have been substantively different from the one actually negotiated. It is questionable, however, whether Intel would have agreed to negotiate a FPA with such groups participating. Indeed, when these and other environmental groups requested that the Intel agreement be augmented with legally-enforceable pollution prevention requirements, Intel was not receptive. Both Intel and 
EPA countered that additional pollution prevention requirements requested by environmental groups would give external actors too much control over the XL process. Although this clearly does not represent the sentiments of all companies regarding all situations, the hesitancy that many firms would feel about sitting down as equal participants with environmental groups in site-specific negotiations is another factor that would tend to limit the success of an initiative such as Project XL. In addition, meaningful involvement of the public, even where it is acceptable to the company, likely would considerably extend the time necessary to develop the FPA.

EPA's more recent statements indicate that the agency's enthusiasm for Project XL has been tempered. Although it is not abandoning the XL initiative, EPA appears to have recognised that the site-specific negotiated solution is fraught with potential problems, and that - like negotiated rulemaking - it cannot be expected to be done successfully without a substantial commitment of time and resources. A Project XL success story makes the point. In 1997, the agency completed negotiations on what has been characterised as a "small, focused" FPA involving an OSi Specialities organo-silicone plant on the Ohio River. According to a company attorney who participated in the process, the negotiations were "enormously burdensome" for the agency. "Unless they can think of a more efficient way to do it," he opined, "I'd be surprised if the program survives." To some degree, of course, the amount of time and resources that the agency currently devotes to a Project XL negotiation is a function of the relative novelty of the XL concept within EPA, the level of mistrust of the XL process within the environmental community, and the pressure on the agency to "make good" on its promise to deliver increased regulatory flexibility without sacrificing environmental goals. Even if Project XL were to one day become a routine part of EPA's activities, however, one would expect the resource demand to continue to be substantial. Real negotiation of environmental policy, even if it is only the policy for a single facility, requires considerable effort.

\subsection{The occupational safety and health administration}

Although the OSHAct gives OSHA a certain amount of discretion as to the manner in which it implements an occupational safety and health standard once the standard has been promulgated, the agency has been slow to sue this discretion as a means of encouraging innovative technological change. Under specified circumstances, OSHA is authorised to grant either a temporary or permanent variance from an OSHAct standard. Requests for variances - which are to be submitted, and evaluated, on an employer-by-employer basis - necessarily provide an opportunity for negotiations between the agency, individual employers, and the affected employees.
Negotiations may cover the length, extent, and conditions of the variance.

Of particular interest is OSHA's authority under section 6 of the OSHAct to grant variances that are determined to be "necessary to permit an employer to participate in an experiment approved by [OSHA]...designed to demonstrate or validate new and improved techniques to improve the health or safety of workers." This broadly-worded provision would appear to give the agency considerable discretion to give extended compliance time to employers who are endeavouring in good faith to perfect promising innovative technologies. Properly utilised and promoted by OSHA, this "experimental" variance provision could be a means of encouraging employers to commit resources to the development of cleaner, safer, and cost-effective workplace technology. It could also be used to promote industry-labour co-operation on technological change in the workplace. To date, however, the agency has largely ignored the opportunities that this provision of the act affords.

\section{Negotiatied compliance}

Roughly $90 \%$ of firms cited with noncriminal violations of federal environmental statutes in the United States resolve the matter through a negotiated settlement (rather than through an administrative hearing or court trial), and the figures appear comparable for the OSHAct setting. The settlement of an enforcement action often offers an agency an excellent opportunity to promote pollution prevention, rather than conventional end-ofpipe control technology. The firm's attention has been commanded, and a need for creative (and less costly) approaches to compliance may well have become apparent. Outside of the enforcement process, an agency has little statutory or regulatory authority to require firms to implement pollution prevention; the regulated community can choose the means by which it will comply with federal requirements. But once an enforcement action is initiated, a window of opportunity for pollution prevention opens, because the means of achieving compliance likely will be subject to negotiation between the agency and the violator.

\subsection{The environmental protection agency's supplemental environmental project (SEP) program}

EPA has sought to capitalise on this opportunity by encouraging the use of Supplemental Environmental Projects (SEPs) to promote pollution prevention. SEPs are environmentally beneficial activities which the violator agrees to perform and/or fund as part of its settlement with EPA, and which the violator is not otherwise legally required to perform. In the settlement process, EPA and company attorneys typically agree both on a 
penalty and on a set of activities designed to achieve and maintain compliance. In 1991, EPA adopted a SEP policy authorising agency enforcement personnel to reduce the amount of the penalty in exchange for the execution of a SEP. Encouraged by initial results from this approach, the agency has revised and expanded its SEP policy since that time.

The key to the SEP policy is the trade-off between penalties and SEPs. Current EPA penalty policy anticipates that, unless the SEP policy is invoked, the penalty assessed in any enforcement action will be the sum of (a) the amount of the economic benefit gained by the violator as a result of non-compliance (typically, the investment earnings from delayed capital expenditures, together with any avoided operation and maintenance costs), and (b) a gravity component (calculated according to agency guidelines) that is meant to reflect the relative seriousness of the violations. Under the present SEP policy, SEPs may be used to reduce this amount, so long as the final penalty paid is at least as large as what EPA characterises as the minimum penalty: the larger of (a) the economic benefit plus $10 \%$ of the gravity component or (b) $25 \%$ of the gravity component.

Currently, there are seven categories of acceptable SEPs: pollution prevention, public health, pollution reduction, environmental restoration and protection, assessments and audits, environmental compliance promotion, and emergency planning and preparedness. The key feature linking these various categories is the expectation that the project will result in some benefit to the environment or public health. Some SEPs, such as an off-site stream restoration project, offer direct, predictable public benefits while returning no direct benefit to the violator. Others, such as an agreement by the violator to conduct a comprehensive environmental audit of its facility, offer potential (and far less predictable) benefits both to the public and to the violator. In general, pollution prevention SEPs - which involve expenditures by the violator to implement technology or practices that reduce its generation of pollution - offer the greatest potential for the development of innovative production technologies and practices with widespread application.

So long as it does not reduce the penalty below the acceptable minimum, EPA will (depending on the assessed merits of the project) credit up to $80 \%$ of the after-tax cost of most approved SEPs (net of any savings - such as reduced operations costs - that the SEP may offer to the violator) against the amount of the penalty. In order to encourage certain types of projects, however, the agency revised its policy in 1995 to offer a credit of up to $100 \%$ for SEPs judged to be "of outstanding quality" according to a set of specified criteria. ${ }^{3}$ Two

\footnotetext{
${ }^{3}$ Five criteria were specified in the 1995 policy: benefits to the public or environment at large; pollution prevention; innovativeness;
}

of the six criteria specified in the most recent version of the SEP policy are: (a) the extent to which the project develops or implements pollution prevention techniques or practices; and (b) the extent to which the project develops or implements innovative technological approaches.

EPA reports that, from Fiscal Year 1992 through Fiscal Year 1994, it negotiated more than 700 SEPs, with an estimated total value (i.e., cost to violators) of over $\$ 190$ million. Of these, approximately $14 \%$ were pollution prevention SEPs, with an estimated total value of approximately $\$ 57$ million. EPA estimates that these pollution prevention SEPs will reduce the discharge of toxic chemicals and the production of hazardous waste by a total of some 65 million pounds.

A case study analysis of ten pollution prevention SEPs negotiated by EPA through Fiscal Year 1992 - selected because they reflect a range of technological responses - found that the technologies utilised included chemical substitution, process change, and closed-loop recycling [8]. Representatives from all nine of the firms involved expressed support for the SEP policy. They indicated that they were glad to have had the option to implement a pollution prevention project in exchange for some penalty reduction, and noted their belief that the SEPs took some of the "sting" out of the enforcement process without eliminating the significant economic and psychological impacts of the enforcement action. Several company representatives also stated that the SEP process helped their firm to recognise other opportunities for environmentally beneficial improvements.

The technological changes undertaken by firms through pollution prevention projects can be categorised according to the locus of the change and according to the degree of innovation of the change. The majority of technological changes made by the SEP case study firms were diffusion-driven. A smaller number can be considered incremental innovations, and only one case can be considered a major innovation. There was a fairly even distribution of technological changes across the spectrum of primary, secondary; and ancillary processes. ${ }^{4}$ If a random case-study selection process had

\footnotetext{
environmental justice; and multimedia impacts. In 1998, a sixth criterion - community input - was added.

${ }^{4}$ Ref. [ 8 at $\left.224 \mathrm{~A}\right]$. The distinction between primary, secondary, and ancillary manufacturing and production processes is an important one for innovation. An example in the context of casting and plating metal screws makes the point. The primary process is the casting of the screw. The secondary process is electroplating. The ancillary process is cleaning or degreasing the screw using organic solvents. If the environmental problems facing the firm is created by the latter activity, it might be relatively easy for the firm to search for and find an alternative, non-polluting cleaning process, and no innovation would be required. If the electroplating is the process that needs to be modified, at least a new process might have to be brought into the firm - usually by the diffusion of alternative plating technology - but the firm would
} 
been used, the sample would have been more heavily weighted toward diffusion-driven changes to ancillary production processes. The larger universe of EPA settlements containing pollution prevention consisted mainly of the adoption of off-the-shelf technologies. This suggests there are unexploited opportunities in enforcement for stimulating innovative technological change. Realisation of this potential likely would require changes in attitudes and knowledge levels, both within industry and within EPA. One move in this direction has been the agency's more recent willingness to allow up to two years for the completion of selected pollution prevention SEPs, as a longer-term time window is essential if more significant innovation is to take place.

\subsection{The occupational safety and health administration}

Unlike EPA, OSHA has not taken creative advantage of the opportunities for negotiation that naturally occur in enforcement situations. As with negotiated implementation, there is much that could be done in this area. For example, rather than simply issuing a citation and imposing a fine for a violation, OSHA could create incentives for employers to design and implement both pollution prevention programs, and "inherent safety" programs to reduce the potential for chemical accidents [9]. While the development of any such initiative by OSHA would need to take care to ensure that the disincentive to violate is maintained, there is no reason why flexibility in enforcement need be incompatible with the integrity of enforcement. Moreover, OSHA could draw from, and perhaps improve on, EPA's extensive experience with its SEP policy.

\section{Regulatory reinvention: EPA's "common sense" initiative}

Under the Clinton Administration, EPA has determined that fundamental changes in approach will be necessary if significant additional progress in protecting the environment is to be made, and if the environmental challenges of the future are to be resolved satisfactorily. The agency refers to this as the need for "regulatory reinvention." In July 1994, EPA began its Common Sense Initiative (CSI), which it has termed the "centrepiece" of its regulatory reinvention efforts. The primary goals of CSI are to find "cleaner, cheaper, smarter" ways of reducing pollution, and to formulate proposed changes

\footnotetext{
be uncomfortable about changing a proven method and taking a chance on altering the appearance of its product, even if it is a separate operation. The most resistance could be expected by demands on the primary process. Here innovation might be necessary, and the firm would not be likely to invest in developing an entirely new casting process merely to reduce a penalty.
}

in the existing regulatory structure to effectuate them. As with Project XI, negotiation among interested parties is the means by which EPA hopes to achieve the goals of the program. Unlike XL, however, the focus of the negotiations is industry-wide. To carry out CSI, the agency has assembled six advisory committees, one for each of six industrial sectors: automobile manufacturing, computers and electronics, iron and steel, metal finishing, petroleum refining, and printing. Each advisory committee consists of representatives from EPA, the relevant industry sector, state and local regulatory agencies, national and local environmental groups, labour, and community organisations. The work of these committees is overseen by a separate Council, the membership of which is drawn from the same sources. The Council is chaired by the EPA Administrator, and each of the six sector committees is chaired by an EPA official. The work of the Council and the committees is assisted by EPA staff.

This industry-sector structure is based on a fundamentally sound premise: that, for a variety of reasons, different industries often differ in their technological and economic potential for reducing pollution, and also in the way in which they respond to various types of regulatory signals. By bringing together people who are knowledgeable about the opportunities for reducing pollution within a particular industry, and who have a stake in how, when, and under what terms that reduction will occur, EPA hoped to harness the potential of each industry to a fuller extent than it had heretofore been able to do. The agency also hoped that, by creating an atmosphere in which innovation and flexibility were emphasised, the focus of the committees would be on pollution prevention rather than end-of-pipe pollution control. And, if the CSI approach proved to be a success, EPA hoped to expand the initiative to other industry segments in the future.

Thus far, the results of the CSI experiment have been mixed. On the one hand, as EPA points out, the initiative has brought together six groups of people representing a diverse set of interests, and has encouraged an ongoing dialogue on issues that are important to the future development of environmental policy. This is a valid point. If CSI succeeds at nothing more than promoting a better understanding of the issues, and of each other, among those likely to participate in environmental policy-making and implementation affecting these industries, it arguably will have had a positive impact.

On the other hand, however, CSI has been criticised for its lack of substantive results. A series of reviews of CSI have raised this issue, including a 1997 report issued by the U.S. General Accounting Office ("GAO"), a research arm of Congress [10] (hereafter "GAO Report"). In general, GAO and other reviewers have found that the CSI process moves considerably more slowly than most of the participants would like. The 
reasons for CSI's slow pace, GAO found, have been multifold: the time necessary to collect and analyse data; the variations in the participants' understanding of the technical issues involved; the time taken by the participants "in reaching consensus on the approaches needed to address large, complex issues or policies;" the time taken by participants "discussing how they would carry out their work and developing their own operating standards;" and the difficulties experienced by some participants in making the necessary time commitment. None of this should be particularly surprising. Indeed, when one adds to this list the overall need to establish a degree of trust among the participants in each sector group sufficient to permit a meaningful discussion on substantive issues, it is not particularly difficult to understand why substantive progress has been slow in coming. Indeed, the fact that the Initiative is still moving forward is itself a measure of progress of some import.

Nonetheless, there appears to be a growing feeling among participants that a failure to meaningfully step up the pace of substantive progress in the near future could mean the death-knell of the Initiative. The automobile and petroleum refining industries have ended their participation, and other participants have indicated that they will leave unless EPA makes changes - in response to the recent reviews of the project - that make for a more efficient process. To address this issue, GAO has proposed that EPA

...provide an improved operating framework that (1) more clearly defines the Initiative's "cleaner, cheaper, smarter" environmental protection goal including its expected results - and (2) specifies how the Council and its subcommittees and workgroups will accomplish their work, clarifying issues such as how and when consensus will be achieved, how the Initiative's goal should be interpreted and applied to individual projects, and to what extent representatives of all stakeholder groups should be included in activities at each level of the Initiative, including its projects and workgroups $[10$, note 13 at 7$] .^{5}$

EPA has indicated that it will introduce reforms of this nature, but GAO faults the agency for not having done much of this at the outset. It is not at all clear, however, that this would have been the right approach. It is arguable that, had EPA attempted to dictate terms of this nature to the participants at the beginning of the process, rather than allowing the participants to first address these issues on their own, it would have engendered considerable resentment among some of the parti-

\footnotetext{
${ }^{5}$ In addition, several environmental justice groups, as well as representatives from the State of Michigan have withdrawn from the CSI negotiations.
}

cipants. Now, armed with numerous meetings' worth of information from the participants as to their thinking on these issues - what is generally agreed to work well and be appropriate, what is generally agreed to work poorly and/or not be appropriate, and what areas will require judicious further definition from the agency EPA is in a position to help create a better framework to help guide these (wholly voluntary) participants.

Moreover, the changes envisioned by GAO are unlikely to address the more deep-seated issues that have slowed or prevented substantive results along the lines originally anticipated by EPA. It is likely that a major factor inhibiting real progress is the fact that, in contrast to negotiated rulemaking, the CSI negotiations are not proceeding within a formal legal context, with a known and meaningful set of potential consequences. In negotiated rulemaking, the participants all know that, regardless of whether they reach agreement on a proposed rule, a rule is likely to be issued. The "stakes" for each participant thus are fairly clear: if we don't negotiate, the agency is going to go ahead and promulgate a regulation without us, and the result may be something we don't like. In the CSI negotiations, however, the consequences of inaction are likely to be both far less clear and far less dramatic. Indeed, in most cases the failure of a negotiating committee to agree on a particular "regulatory reinvention" proposal will have no greater practical effect than simply the preservation of the status quo.

Accordingly, the chief factor likely to be motivating industry's participation in the CSI negotiations is the opportunity to push for regulatory alternatives that are less expensive (to industry) than the status quo. Industry's interest, then, is likely to be in "streamlining" or eliminating - current regulation, and not in extending the scope of regulation into new areas. And, since the environmental representatives should not be expected to agree to a cheaper alternative if it does not also represent increased environmental benefit, progress may be slow in coming, especially in those industry sectors where few easy and obvious "win/win" (i.e., cheaper and cleaner) regulatory improvements present themselves.

Thus, it should not be surprising that the petroleum and automobile industries decided to abandon their participation in the CSI Initiative. Effective participation in negotiations of this nature takes a considerable commitment of resources. As noted by the American Petroleum Institute in a letter to EPA explaining the withdrawal of its member companies from the CSI negotiations, the companies "believe the refining industry's resources...can be more productively directed toward other approaches."

Another systemic problem one would expect to encounter in negotiations of this nature stems from the participants' unequal access to relevant data. If effective strategies to encourage pollution prevention are to be 
crafted by consensus, reliable technical information especially information relating to the technological potential for pollution prevention - is likely to be important. Much of the relevant data, of course, will be in the hands of industry. Without a clear incentive to make these data available to the other participants, industry is likely to prefer to pick and choose what it will share, thus making meaningful negotiations all the more difficult. This reportedly has been a major issue, for example, in the computer and electronics work group. Firms reportedly have been reluctant to divulge information because "they feared that regulators would use data to extract further concessions," and because they believed that environmental groups would "use any information divulged during CSI meetings to mount lawsuits." This, in turn, contributed to a sense of mistrust among the environmental group participants.

This is not to say that CSI is not likely to produce any meaningful results of substance. There are cleaner/cheaper opportunities in a number of industries that may be able to be realised without the "push" of additional regulatory pressure, and CSI can be expected to bring some of these to light. The metal finishing work group, for example, began a successful demonstration of a new technology for filtering chromium from air releases that should decrease chromium emissions while reducing costs by about $90 \%$, and has announced agreement on an emission reduction program that may well rely, in part, on pollution prevention strategies. And the printing work group has been developing an education and outreach project designed "to achieve fundamental change" by incorporating the philosophy of pollution prevention into everyday work practices. In general, however, the bulk of the CSI negotiations thus far reportedly have not focused on pollution prevention strategies. If this does not change, the CSI experiment will have fallen well below EPA's original expectations.

\section{Conclusion}

Negotiation should hardly be viewed as a panacea for the various difficulties that typically confront the policymaker. Used in the right context, however, negotiation can be a useful tool in the establishment, implementation, and enforcement of environmental and occupational safety and health policy. Negotiation can facilitate a better understanding of issues, concerns, facts, and positions among adversaries. It can also promote the sharing of relevant information, and can provide an opportunity for creative problern-solving. Whether negotiation will be better than other, generally more adversarial mechanisms as a means of fostering improved environmental, health, and safety outcomes, or of stimulating meaningful technological change, will depend on the situation in which it is used. In general, negotiation would appear to work best a means of securing these goals in situations in which the necessary regulatory signals for improvement and innovation are already in place.

This is one of the reasons that EPA's use of negotiated compliance, as embodied in its SEP policy, has been as successful as it has been. To the firm that is the target of the enforcement action, the "stakes" are clear: so long as it believes it faces higher costs (in the form of a larger fine and/or higher transaction costs) if it does not identify and execute a SEP that is acceptable to EPA, the firm has a meaningful incentive to participate in good faith in the SEP process. And, because the agency has structured the program to allow maximum credit for pollution prevention projects, pollution prevention can become the focus, and the goal, of the negotiations. The pollution prevention results of the SEP program have been relatively modest - mostly diffusion and, sometimes, incremental innovation - but this is in keeping with the relatively modest nature of the financial incentives typically involved, and with the relatively short time period within which the SEP typically must be identified and completed. Especially because negotiation is the traditional means of resolving enforcement disputes, even outside of the SEP process, negotiation appears to work well here. OSHA would be well-advised to design a policy of its own to take advantage of the opportunities for positive technological changes that arise in appropriate enforcement situations.

One would also expect negotiation to work well in those negotiated implementation situations that have a clear, formal focus on technological change, such as the innovation waiver opportunities created by certain environmental statutes, and the "experimental" variance authorised by the OSHAct. The chief signal to innovate - the new regulatory standard - is already in place (or clearly on the horizon) before negotiation over the waiver or variance begins, and the statutes typically provide an extended period of time for the firm to develop and test the proposed innovation. Thus, so long as the new standard is stringent enough to command the firm's attention, firms should have a meaningful incentive to negotiate time to pursue an innovative compliance alternative.

The fact that EPA's innovation waiver program has thus far not lived up to expectations appears largely due to a failure of administration. This, in turn, may have contributed to what appears to be a reticence by Congress to include innovation waiver provisions in its revisions to existing statutes. If EPA could develop and promote its innovation waiver program the way it has the SEP program, the innovation waiver might become a much more important means of securing environmentally beneficial technological change. Similarly, although OSHA has not made significant use of its experimental variance authority in the past, there is good reason to 
believe that this provision could be a force for technological change. OSHA should develop a set of criteria to help define those situations in which a variance of this nature could be used productively, and should publicise the availability of this option when it promulgates a standard. The agency should then work with employers to help them identify opportunities for innovative technological responses.

In contrast to negotiated compliance and negotiated implementation, negotiated rulemaking is a situation in which the chief regulatory signal for improvement and innovation is not already established, at least not in full. Rather, one of the functions of negotiation in this context is to establish, either in part or in full, the stringency of the regulatory standard. If the goal is innovation, this may well be problematic. If the nature of the regulated industry is such that it will require a dramatic impetus such as the promulgation of an unexpectedly stringent standard, or the fear that such a standard will be promulgated - before it will be motivated to innovate, negotiated rulemaking may well be inadvisable. Since negotiated rulemaking seeks consensus among the participants, and since such an industry is unlikely to agree to a standard that it views as having a "dramatic" impact, negotiated rulemaking is unlikely to produce a standard of this nature. In such situations, negotiated rulemaking's focus on consensus can effectively remove the potential to spur innovation [11]. In situations in which the desired technological change is likely to come more easily, negotiated rulemaking should be expected to have a better chance of success. Here, the advantages of negotiation, such as information-sharing and creative problem-solving, may work to encourage productive technological change. The key to the willingness of industry representatives to explore the technological options in good faith is likely to be tied to what they perceive the likely "default" standard to be. If they believe that, in the absence of a negotiated rule, the agency will promulgate a stringent rule on its own, their willingness to focus on creative technological solutions is likely to be higher. The agency can facilitate this process by making clear at the outset that promoting technological change will be a focus of the regulation. If technologically literate stakeholders, such as trade unions or sophisticated non-profit groups, are involved, the dominance of industry's technical expertise may be minimised, and outcomes that advance the state of the technology may emerge.

Another important difference between negotiated rulemaking and negotiations over SEPs and innovation waivers, however, is that the scope of the negotiations in negotiated rulemaking is (at least) industry-wide, rather than firm-specific. Interest in the negotiations thus is much stronger, and the number of participants who must be involved, if the negotiations are to succeed, is an order of magnitude higher. Accordingly, management of the negotiation process becomes a formidable task, and the agency must have the resources to be able to keep pace. There is always the risk that the process itself, and not the ultimate results of the process, will assume centre stage, and that a focus on technological change will give way to a focus on achieving consensus.

Many of these same concerns will be at hand when negotiation is used in an extra-statutory sense, as it is now being used in EPA's Project XL and Common Sense Initiative (CSI), in an attempt to change regulatory policy. If the focus is industry-wide, as it is with CSI (and is often perceived to be with Project XL), the resource demands will be large. Further, where there is no meaningful incentive for industry negotiators to move away from the status quo - that is, where there is no impending "default" standard or requirement that they perceive as onerous - they may well be interested only in those regulatory changes that save them money.

In the last analysis, it must be recognised that negotiation is a process that facilitates market solutions to questions regarding the appropriate ends or means of compliance. That is, the relative bargaining power of the stakeholders largely determines the outcome, unless it is checked at the end of the process by a government agency with a strong sense of trusteeship for the congressional policy it is charged with implementing. Agencies who see themselves as mediators of the negotiation, or who otherwise relinquish their statutory role as trustees, help to promote a market-like result through the operation of the consensus process. For example, when OSHA abdicates its policy-making responsibility by making clear to industry and labour that it will accept a negotiated settlement as the basis for occupational safety and health standards, the chances that negotiation will produce meaningful safety and health gains are reduced considerably. When this happens, the relative success of the negotiations likely will depend on whether some other factor - such as a court ruling or a scientific study - can produce the kind of incentives that are likely to promote technological change. If a superior result is to be achieved, it likely will require the participation of agencies with both the means and the will to take a firm position in support of health, safety, and the environment, and in support of the development of new technologies.

\section{Acknowledgements}

The authors gratefully acknowledge the Fondazione Eni Enrico Mattei for its súpport of the research underlying this Article. It is based on a more extensively documented work: Caldart CC, Ashford NA. A negotiation as a means of developing and implementing environmental and occupational health and safety policy. Harvard Env. Law Rev. 1999;23(1):141-202. 


\section{References}

[1] Coglianese $\mathrm{C}$. Assessing consensus: the promise and performance of negotiated rulemaking 46 Duke LJ, 1997.

[2] Perritt H Jr.. Negotiated rulemaking before federal agencies: evaluation of recommendations by the administrative conference of the United States. Georgetown Law J 1986;74:1625-82.

[3] Congress of the United States. Office of technology assessment, gauging control technology and regulatory impacts in occupational safety and health - an appraisal of 'OSHA's analytic approach, OTA-ENV-635. Washington, DC: US Government Printing Office, September 1995.

[4] Ashford N, Caldart C. Technology, law, and the working environment. Island Press, 1997.

[5] Ashford N. Government regulation of occupational health and safety, in occupational health: recognizing and preventing workrelated disease. 3rd edition, Boston: Little Brown, 1999 (in press).

[6] Ashford N, Ayers C, Stone R. Using regulation to change the market for innovation. Harvard Env Law Rev 1985;9(419):443-62.
[7] Office of Water, US EPA. Providing waivers from NPDES permit compliance for industrial pollution prevention technology: the industrial pollution prevention project (IP3). Analysis of Sections 301(K) and 307(E) of the Clean Water Act, 1994.

[8] Becker M, Ashford N. Exploiting opportunities for pollution prevention in EPA enforcement agreements. Env Sci Tech 1995;29(5):220A-6A.

[9] Ashford N, Gobbel J, Lachman J, Matthiesen M, Minzer A, Stone $R$. The encouragement of technological change for preventing chemical accidents: moving firms from secondary prevention and mitigation to primary prevention. A report to the US Environmental Protection Agency, Center for Technology, Policy and Industrial Development, Massachusetts Institute of Technology, Cambridge, Massachusetts, July 1993.

[10] United States General Accounting Office. Regulatory reinvention: EPA's common sense initiative needs an improved operating framework and progress measures, July 1997.

[11] Goulding A, Murphy J. Regulatory realities: the implementation and impact of industrial environmental regulation. London: Earthscan Publications Ltd, 1998. 